\title{
Somatic embryogenesis and plant regeneration from cotyledonary node's calli of Trigonella foenum-graecum $\mathrm{L}$. \\ تكوين الأجنة الجسمية وإخلاف النباتات من كالس العقد الفلقية لنبات الحلبة
}

Trigonella foenum-graecum $\mathrm{L}$.

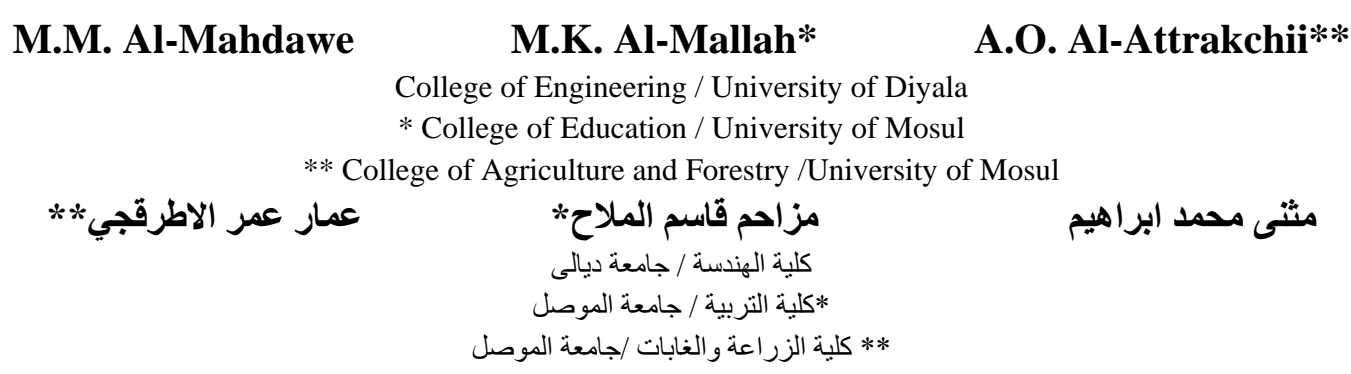

\section{Abstract}

The present study describes plant regeneration via somatic embryogenesis from cotyledonary node callus. Callus cultures were derived from cotyledon node segment excised from Trigonella foenum-graecum L. axenic seedlings grown in agar solidified Murashing and Skoog's(MS) medium supplemented with Benzyl adenine BA at 2.0 $\mathrm{mg} \mathrm{l}^{-1}$ and Naphthalene acetic acid NAA at $1.0 \mathrm{mg} \mathrm{l}^{-1}$. These cultures were stimulated to form somatic embryoids at $32 \%$ frequency of in agar-solidified MS medium containing NAA at $0.5 \mathrm{mg} \mathrm{I}^{-1}$ in the presence of $15 \% \mathrm{v} / \mathrm{v}$ coconut water. Light microscopy examination of sections of heart embryos stage proved the presence of vascular system. Transfer of other developmental stages of embryos to the same induction medium led to the development of secondary somatic embryos and embryoids into plantlets in agar-solidified MS medium lacking hormones. They were readily rooted in MSO and successfully transferred to soil.

تصف الدراسة الحالية أخلاف النباتات من الأجنة الجسمية المتكونة من كالس العقد القلقية المستأصلة من العقد

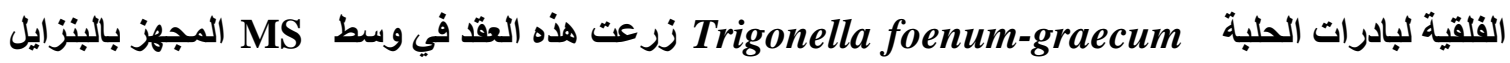

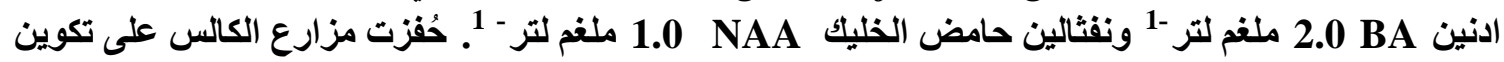

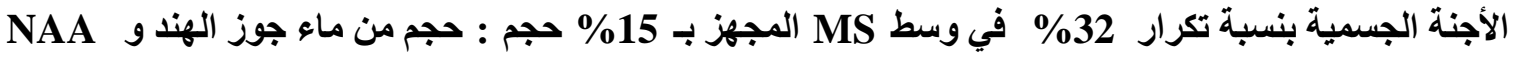

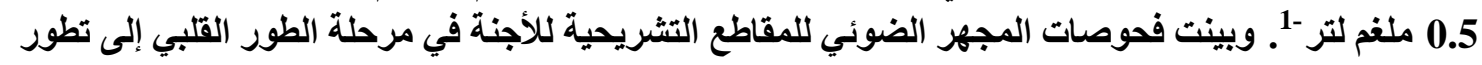

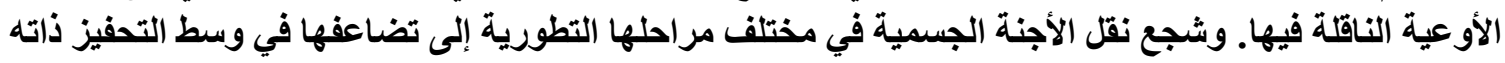

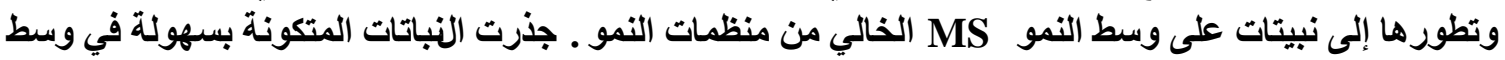
MSO

\section{Introduction}

Plant tissue culture systems have been developed for Fenugreek Trigonella foenumgraecum L., which utilize either shoot morphogenesis [1] or somatic embryogenesis [2] as the route regeneration. This embryogenesis occurs directly from explants, or indirectly from callus [3]. Further argued that the morphological and temporal development of somatic embryos are very similar to that of zygotic embryos, and that they both proceed through a series of distinct stages, namely globular, heart, torpedo, and cotyledon or plantlet stages in dicotyledons [4]. Somatic embryo is a versatile technique of micropropagation of various herbaceous plant species belong to leguminous family e.g., key words: Somatic embryogenesis, Cotyledonary node's calli, Trigonella foenum-graecum $\mathbf{L}$. 
Glycine max [5], Arachis glabrata [6], Astragalus chrysochlorus [7], Desmodium gangeticum [8]. This method of micropropagation offers several advantages over organogenesis and clonally propagation through explants: Somatic embryos grow individually making the system easy to manipulate (to subculture) and developing scaling-up methods and offer the possibility to produce somatic embryos in cell cultures and use of bioreactors for scale-up technology and presence of bipolar structures in the same unit (presence of both root and shoot) avoids the rooting step required in organogenesis [9].

Trigonella foenum-graecum L. is an important medicinal legume plants used as vegetable and spices [10].

The current work describes an efficient protocol of somatic embryogenesis from cotyledon node callus to overcome the barrier of shoot regeneration in this plant species.

\section{Materials and Methods}

\section{1- Callus induction and maintenance}

Seeds, of Trigonella foenum-graecum L., were obtained from local market. It was washed in running tap water, surface disinfected in a $3 \%$ solution of $\mathrm{NaOCl}$ for $5 \mathrm{~min}$. and finally rinsed with sterile distilled water for three times. Sterilized seeds were germinated on agar- solidified MSO (hormone-free) medium [11] and maintained in dark for three days at $25 \pm 2^{\circ} \mathrm{C}$. The produced plantlets were maintained at $25 \pm 2^{\circ} \mathrm{C}$ in the light at 700 lux with a daily $16 \mathrm{~h}$ photoperiod [12]. Cotyledon nodes were excised from 15 days old plantlets, these explants were sliced into lengths of $0.5 \mathrm{~cm}$ and placed horizontally on the surface of callus-induction MS medium supplemented with $2.0 \mathrm{mg} \mathrm{l}^{-1} \mathrm{BA}$ and $1.0 \mathrm{mg} \mathrm{l}^{-1}$ NAA [13]. Cultures were maintained under the same as above conditions.

\section{2- Induction of somatic embryos}

Cotyledon node-derived calli were cultured on three types of media including multiplication medium (MSNCW) which consist from; $\mathrm{MS}+0.5 \mathrm{mg} \mathrm{l}^{-1} \mathrm{NAA}+$ Coconut water (CW) $15 \% \mathrm{v} / \mathrm{v}$ [14], and MSNB medium which consist of ; $\mathrm{MS}+2.0 \mathrm{mg} \mathrm{l}^{-1} \mathrm{NAA}$ $+0.5 \mathrm{mg} \mathrm{l}^{-1} \mathrm{BA}$ [2], and on MSD media ; MS+1.0 $\mathrm{mg} \mathrm{l}^{-1} 2,4-\mathrm{D}$. Coconut water was collected from fresh nuts (obtained from the greengrocer), this is usually strained through cloth and deproteinized by being heated to $80-100^{\circ} \mathrm{C}$ for about $10 \mathrm{~min}$. while being stirred, it is then allowed to settle and the supernatant is separated from the coagulated proteins by filtration through paper. The liquid is stored frozen at $-20^{\circ} \mathrm{C}$ [15]. Tissues were subcultured at the thirty days' interval, during subculture $100 \mathrm{mg}$ fresh weight callus was used as inoculums. The cultures were maintained at $25 \pm 2^{\circ} \mathrm{C}$ under a photoperiod $(16 \mathrm{~h} / 8 \mathrm{~h})$ used for plantlets formation in agar solidified MSO medium at ten replicates in each treatment.

\section{3- Embryos sectioning.}

Free-hand sections method was used, embryonic heart stage samples were sliced into 2-3 mm thickness longitudinal sections by fresh-mediated models of sharp blade. Sections were staind with solution of $1 \%$ Safranin O (Sigma-Alderich, UK) transported immediately on glass slides, and examined using light microscopy [16] . 


\section{4- Plant regeneration and multiplication.}

Approximately fifty $\mathrm{mg}$ of cotyledonry callus were placed on the surface of regeneration medium containing MS salts or multiplication medium (MSNCW) and incubated under the same conditions used for initiation of ermbryogenic callus cultures. The developed shoots were excised and transferred separately to fresh regeneration MSO medium for rootin [13].

\section{Results}

\section{1- Somatic embryos growth development}

The results indicate the formation of callus easily from three weeks old cotyledonary node explants on MS medium supplemented with $2.0 \mathrm{mg} \mathrm{l}^{-1} \mathrm{BA}+1.0 \mathrm{mg} \mathrm{l}^{-1} \mathrm{NAA}$ Figure (1.A). Transfer of this callus to medium consisting of MS base salts $+15 \%$ coconut water $+0.5 \mathrm{mg} \mathrm{l}^{-1} \mathrm{NAA}$ enhanced the occurrence of somatic embryogenesis by viewing numerous green and undistinguishable structures Figure (1.B). Somatic embryos were observed by naked eye after 30 days of callus transfer, various embryos developmental stages, and the formation of cotyledonary embryos structures after the fourth subculture Figure (1.C).
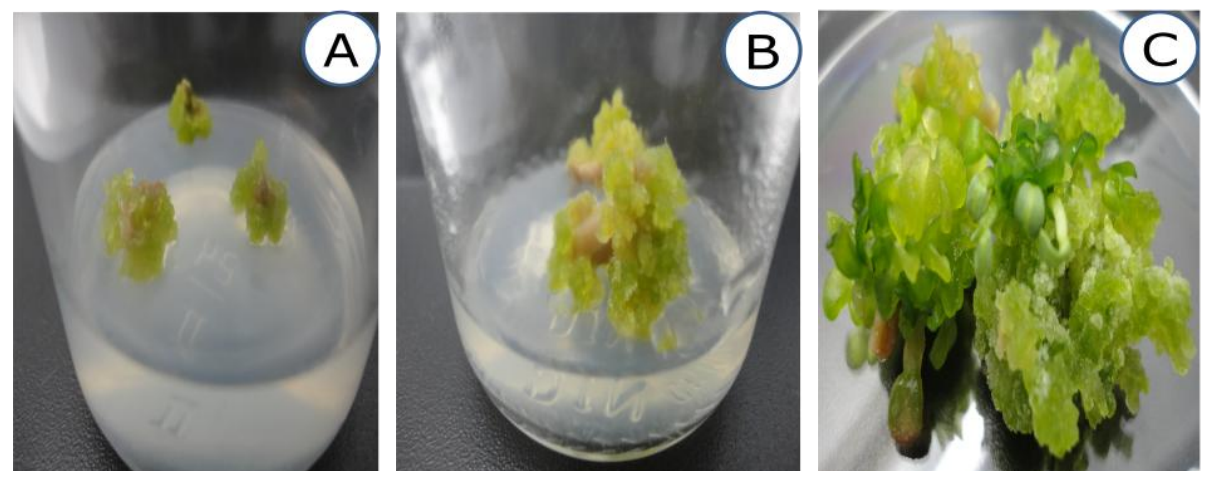

Fig (1): Induction of somatic embryos from cotyledon node explants of Trigonella foenum-graecum. (A) callus induction on $\mathrm{MS}+2.0 \mathrm{mgl}^{-1} \mathrm{BA}+1.0 \mathrm{mgl}^{-1} \mathrm{NAA}$. (B) Formation of numerous green structures on callus in (A) grown on stimulation media MS+ coconut water $15 \%+0.5 \mathrm{mgl}^{-1}$ NAA. (C) Development of cotyledonary embryos on callus in (B) after $4^{\text {th }}$ subcultures on stimulation media

Murashige and Skooge medium containing $2.0 \mathrm{mg} \mathrm{l}^{-1} \mathrm{NAA}+0.5 \mathrm{mg} \mathrm{l}^{-1} \mathrm{BA}$ stimulate the formation of many structures similar to embryos globular stage but failed to develop further. The results proved that multiplication medium (MSNCM) superiority was clear Table (1).

Table (1): Numbers of somatic embryos stages produced from cotyledon node callus of Trigonella foenum-graecum in three different media

\begin{tabular}{ccccc}
\hline $\begin{array}{c}\text { Induction } \\
\text { media }\end{array}$ & Globular & Heart & Torpedo & Cotyledon \\
& & & & \\
MSNCM & 32 & 31 & 26 & 25 \\
MSNB & 30 & 0 & 0 & 0 \\
MSD & 0 & 0 & 0 & 0 \\
\hline
\end{tabular}

The MSNCM medium encourages the formation of many embryogenic masses Figure (2.A) which develop later to globular stage compared with the other stimulation media Figure (2.B). Total numbers of 32 embryos were turned after first subculture and 
subsequently developed after 60 days to heart stage Figure (2.C). Majority of these heart embryos were start to elongate and transformed to torpedo stage Fig (2.D) at the $3^{\text {rd }}$ subculture, and most of them pass to the differentiated cotyledon stage Figure (2. E,F). Light microscopy examination of embryos sections refers clearly Figure (2.G) to the development of vascular system in these somatic embryos. This is proving strongly the evolutionary state and the beginning of differentiation to organs.
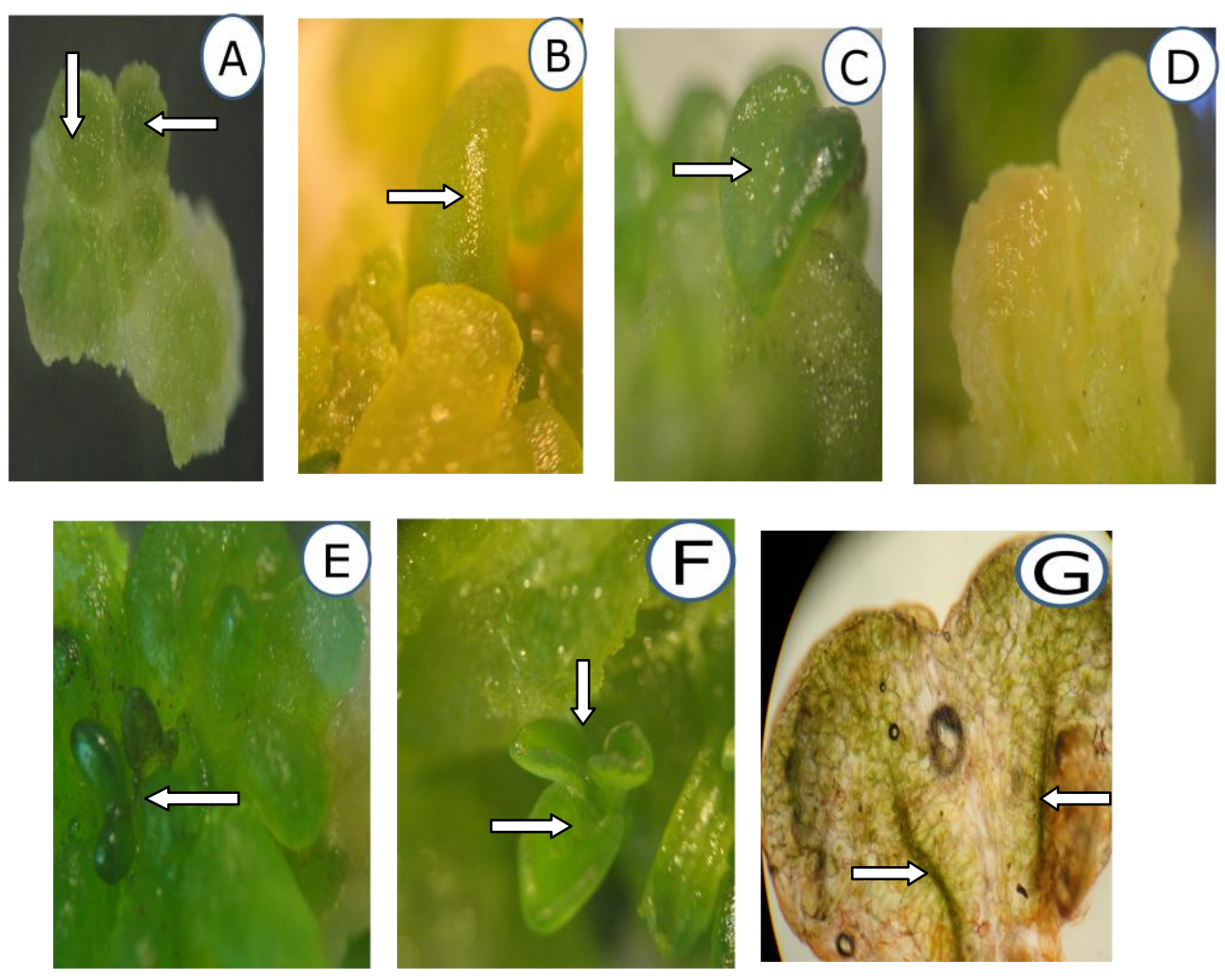

Fig (2): Embryos different stages (bar=0.4mm) developed from node callus of $T$. foenum-graecum (A) Embryogenic masses formed after 21 days (arrows). (B) Development of globular shape embryos in (A) (arrow). (C) Heart shape embryo stage(arrow). (D) Torpedo stage embryo. (E) Cotyledonary stage embryo (arrow). (F) Embryos germination and leaf proliferation (arrows). (G) Longitudinal sections showing the vascular system of somatic embryo $(\mathrm{bar}=400 \mu \mathrm{m})($ arrows).

\section{2- Transfer of embryos and plant regeneration}

The results found that transfer of somatic embryos masses, each containing 3-4 embryos, will pass through various stages of embryogenesis in the same stimulating medium and produce cluster of 10-15 embryos from each piece figure (3.A). They were pale-green in color everlasting and preventing the emergence of vitrification figure (3.B).

\section{3- Rooting and transfer}

These embryos were able to grow producing numerous fenugreek plants on MSO medium figure (3.C). 

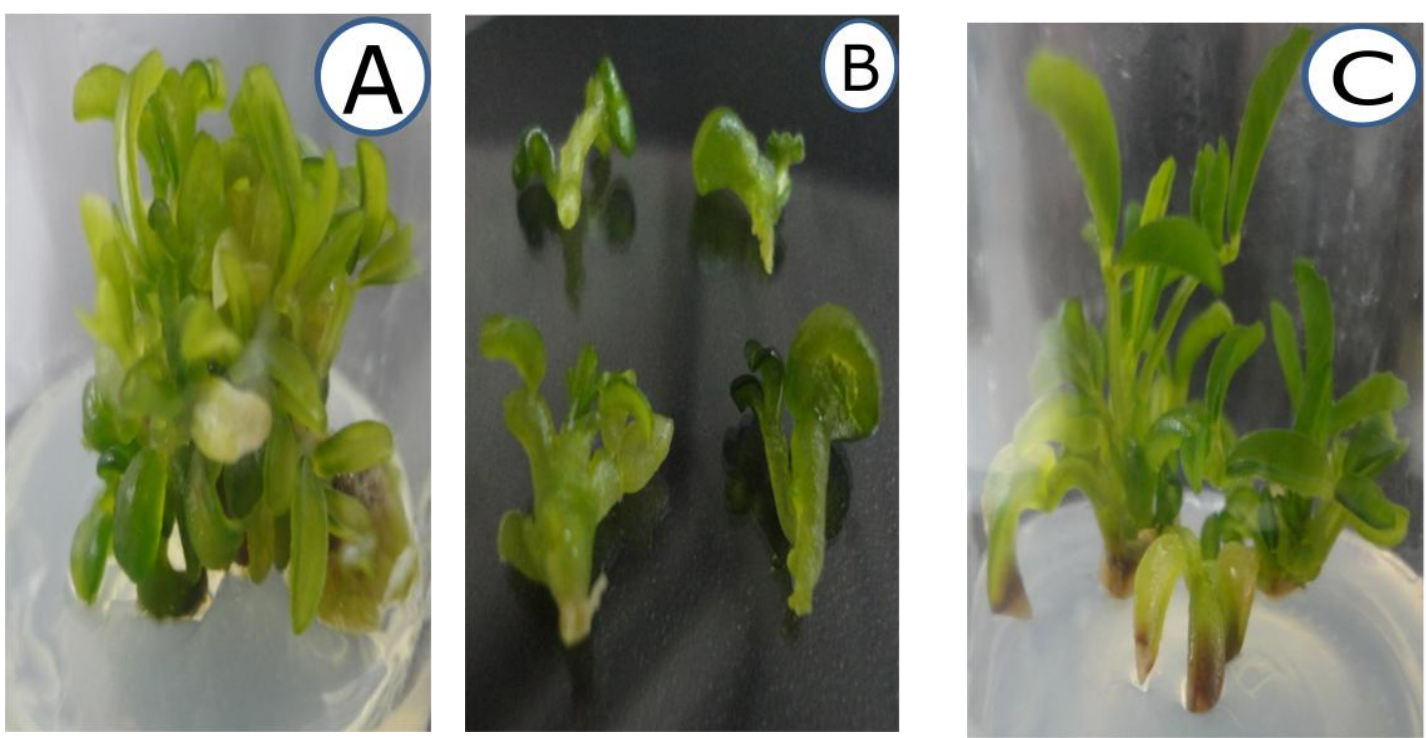

Fig (3): Regeneration of T. foenum-graecum plantlet and multiplication stage . (A) Secondary somatic embryos on stimulation media. (B) Somatic embryos excise in (A). (C) True leaves (arrows) expanded and a whole plantlet was established on MSO media

\section{Discussion}

Somatic embryogenesis phenomenon based on two steps, the first include the induction of embryogenic competence (referred to as embryogenic masses or clumps), in the presence of high concentration of auxin. The second step involved the development of embryogenic cell into embryos in absence or in presence of lower concentration of auxin. There are exceptional cases, like carrot, where auxin did not required for somatic embryogenesis and its presence can inhibit the somatic embryogenesis, and embryo development may be achieved in absence or in presence of lower auxin and cytokinin concentration [9]. This study demonstrates the effect of the bioactive compounds of coconut water that usually had an important role in differentiation, and has been identified as enhancers of somatic embryogenesis. Its efficacy in embryogenesis has been attributed to their contribution to various cellular processes, such as improving cell signaling processes in various signal transduction pathway [17] . Again, coconut water also contains substances identified as components include amino acids, organic acids, sugars, sugar alcohols and minerals [18], vitamins and growth substances [19]. Other investigators have emphasized that the inclusion of complex organic extracts, such as coconut water are essential for somatic embryogenesis in Doritaenopsis orchid [20]. Moreover, it has also been proposed that these organic extracts are either non-mutagenic or less mutagenic in comparison to conventional growth regulators and, as such, their incorporation in the culture media may minimize somaclonal variations [21]. The authors found that the ability of high plant regeneration from cotyledon node directly (unpublished data) or indirectly through somatic embryogenesis may due to the presence of meristemoids a certain types of cells. The facts that these cells are responsive to influantial genetic organic such as the ratio between auxin and cytokinins [22]. Many investigators mentioned that coconut water can stimulate the growth of some in vitro cultures, in the absence of exogenous auxins; this is almost certainly, due to its supply of 
highly active natural cytokinin growth substances. Although, it has been found to have some auxin activity which increased by autoclaving probably because such growth substances exist in abound form and are released by hydrolysis. This means that a beneficial effect in growth or morphogenesis is often dependent on the presence of an auxin [23]. Other study found a synergistic action between NAA and coconut water in stimulating bud-like structures on leaf callus of Trigonella corniculata [14]. In conclusion, the results obtained in this study may cooperate in overcoming problems arise in plant regeneration from certain types of callus of other leguminous plants.

\section{References}

1. Aasim, M., Hussain, N., Umer, E. M., Zubair, M., Hussain, S.B., Saeed, S., Rafique, T. S. and Sancak, C. (2010). In vitro shoot regeneration of fenugreek (Trigonella foenum- graecum L.) using different cytokinins. Afric. J. Biotech. 9: 7174-7179.

2. Lu, D.Y., Davey M.R. and Cocking, E.C. (1982). Somatic embryogenesis from mesophyll protoplasts of Trigonella corniculata (Leguminosae). Plant Cell Repts. 1:278-280.

3. Razdan, M. K. (2003). Introduction to Plant Tissue Culture. Science Publishers Inc. USA, third edition.

4. Zimmerman, J.L. (1993). Somatic embryogenesis: a model for early development in higher plants. The Plant Cell. 5: 1411-1423.

5. Finer, J.J. and Nagasawa, A. (1988). Development of an embryogenic suspension culture of soybean (Glycine max Merrill.). Plant Cell, Tiss. \& Org. Cult. 15:125136.

6. Vidoz, M.L.,Rey, H.Y., Gonzalen, A.M. and Mroginski, L. A. (2004). Somatic embryogenesis and plant regeneration through leaf culture in Arachis glabrata (Leguminosae). Acta Phys. Planta. 26: 59-66.

7. Hasancebi, S., Kara, N.T., Cakir, O. and Ari, S. (2010). Micropropagation and root culture of Turkish endemic Astragalus chrysochlorus (Leguminosae). Turk J. Bot. 35:203-210.

8. Puhan, P. and Rath, S.P. (2012). Induction, development and germination of somatic embryos from In vitro grown seedling explants in Desmodium gangeticum L.: a medicinal plant. Res. J. Medic. Plant. 6: 346-369.

9. Ramawat, K. G. (2008). Plant Biotechnology. S. Chand and Company Ltd. New Delhi, Indian, $3^{\text {th }}$ ed.

10. Khan, M.B., Khan, M.A. and Sheikh, M. (2005). Effect of phosphorus levels on growth and yield of fenugreek. Int. J. Agric. Biol. 7:504-507.

11. Murashige, T. and Skoog, F. (1962). A revised medium for rapid growth and bioassays with tobacco cultures. Physiol. Plant. 15: 473-497.

12. Merkli, A., Christen P. and Kapetanidis, I. (1997). Production of diosgenin by hairy root cultures of Trigonella foenum-graecum L. Plant Cell Repts. 16:632-636.

13. Al-Mallah, M.K. and Yaseen, J.M. (2000). One step plant regeneration from stemderived callus of the medicinal plant Trigonella foenum-graecum L.J.Edu. \& Sci. 46: 17-27. 
14. Sen, B. and Gupta, S. (1979). Differentiation in callus cultures of leaf of two species of Trigonella. Physiol. Plant. 45:425-428.

15. Borkird, C. and Sink, K.C. (1983). Medium components for shoot cultures of chlorophyll-deficient mutants of Petunia inflate. Plant Cell Repts. 2:1-4.

16. Purvis, M.J., Collier D.C. and Walls, D. (1966). Laboratory Techniques in Botany, second edition, London Butterworths.

17. Lakshmanan, P. and Taji, A. (2000). Somatic embryogenesis in leguminous plant. Plant Biol. 2: 136-148.

18. Tulecke, W., Weinstein, L.H., Rutner A. and Laurencot, H.J. (1961). The biochemical composition of coconut water as related to its use in plant tissue culture. Contrib. Boyce Thomps. 21: 115-128.

19. Dlx, L. and Van Staden, J. (1982). Auxin and gibberellins-like and vitamins substances in coconut water and malt extract. Plant Cell, Tiss. \& Org. Cult. 1: 239245 .

20. Islam, M.O., Rahman, A.R.M.M., Matsui, S. and Prodhan, A.K.M.A. (2003). Effects of complex organic extracts on callus growth and PLB regeneration through embryogenesis in the Doritaenopsis orchid. Jap. J. Agricul. Res.Quarterly. 37: 229-235.

21. Lam, T. W., Ernst, R., Arditti J. and Ichihashi, S. (1991). The effects of complex additives and (6- y-Dimethyl allylamino )- purine on the proliferation of Phalaenopsis protocorms. Lindleyana. 6: 24-26.

22. Torrey, J.G. (1966). The initiation of organized development in plants. Adv. Morphog, 5:39.

23. George, E. F., Hall M.A. and De Klerk, G.J. (2008). Plant Propagation by Tissue Culture. $3^{\text {rd }}$ edition, Springer. The Netherlands. 